\title{
Announcing a New Book
}

$\mathrm{T}$ HE following book has been announced on the Nova Science Publishers website: Oxide Electronics and Functional Properties of Transition Metal Oxides https://www.novapublishers.com/catalog/product_info.php? products id=50601, ISBN: 978-1-63321-499-6.

Table of Contents:

- Oxide Electronics: An Introduction (A. L. Pergament, Petrozavodsk State University, Petrozavodsk, Russia).

- Chapter I. Unipolar Resistive Switching Effect (T. V. Kundozerova and G. B. Stefanovich, Petrozavodsk State University, Petrozavodsk, Russia).

- Chapter II. Some Fundamental Points of Technology of Lithium Niobate and Lithium Tantalate Single Crystals (M. N. Palatnikov and N. V. Sidorov, I. V. Tananaev Institute of Chemistry and Technology of Rare Elements and Mineral Raw Materials, Apatity, Russia).

- Chapter III. Sputter Deposited Nanolaminates Containing Group IVB (Ti, Zr, Hf)-Oxides: Phase Structure and Near Band Gap Optical Absorption Behavior (C. R. Aita, University of WisconsinMilwaukee, WI, USA).

- Chapter IV. Optical and Electrical Switching of Thermochromic $\mathrm{VO}_{2}$ Smart Coatings (M. Soltani, RSL-Tech 9114 Descartes, Montreal, QC, Canada).

Book Description:

MOSFETs (Metal-Oxide-Semiconductor Field-Effect Transistors) for a long time have been the workhorse of the modern electronics industry. For the purpose of a permanent integration enhancement, the size of a MOSFET has been decreasing exponentially for decades in compliance with Moore's Law, but nowadays, owing to the intrinsic restrictions, the further scaling of MOSFET devices either encounters fundamental (e.g. quantum-mechanical) limits or demands for more and more sophisticated and expensive engineering solutions. Alternative approaches and device concepts are being currently designed both in order to sustain an increase of the integration degree, and to improve the functionality and performance of electronic devices. Oxide electronics is one such promising approach which could enable and accelerate the development of information and computing technology. The behavior of d-electrons in transition metal oxides (TMOs) is responsible for the unique properties of these materials, causing strong electron-electron correlations, which play an important role in the mechanism of metalinsulator transition. The Mott transition in vanadium dioxide is specifically the effect that researchers consider as one of the most promising phenomena for oxide electronics, particularly in its special direction known as a Motttransition field-effect transistor (MTFET). Therefore, $\mathrm{VO}_{2-}$ based MTFET is one of the fields of oxide electronics. Also, oxide ReRAM is another rapidly growing field of oxide electronics. Finally, many other functional properties of TMOs, including for example, optical and electrical switching of thermochromic $\mathrm{VO}_{2}$ smart coatings, optical properties (especially Raman spectra) of single crystalline lithium niobate and tantalate $\left(\mathrm{LiNbO}_{3}\right.$ and $\left.\mathrm{LiTaO}_{3}\right)$, as well as optical properties (near band gap optical absorption) of TMO-based nanolaminates, like e.g. $\mathrm{ZrO}_{2}-\mathrm{Al}_{2} \mathrm{O}_{3}, \mathrm{HfO}_{2}$ $\mathrm{Al}_{2} \mathrm{O}_{3}, \quad \mathrm{TiO}_{2}-\mathrm{Al}_{2} \mathrm{O}_{3}, \quad \mathrm{ZrO}_{2}-\mathrm{TiO}_{2}$, and $\mathrm{HfO}_{2}-\mathrm{TiO}_{2}$, are extremely important to understand and estimate the potential ability of different TMOs and TMO-based structures in diverse fields of oxide electronics.

Alexander Pergament Associate Editor

June 2014 